International Journal of Advanced Trends in Computer Science and Engineering

Available Online at http://www.warse.org/IJATCSE/static/pdf/file/ijatcse01932020.pdf

https://doi.org/10.30534/ijatcse/2020/01932020

\title{
Assessment tools in e-learning Moodle
}

\author{
Olga I. Vaganova ${ }^{1}$, Zhanna V. Smirnova ${ }^{2}$, Ekaterina V. Vezetiu ${ }^{3}$, Maxim M. Kutepov ${ }^{4}$, \\ Elena A. Chelnokova ${ }^{5}$ \\ ${ }^{1}$ Minin Nizhny Novgorod State Pedagogical University, Nizhny Novgorod, Russia, vaganova_o@ $@$ rambler.ru \\ ${ }^{2}$ Minin Nizhny Novgorod State Pedagogical University, Nizhny Novgorod, Russia, \\ z.v.smirnova@mininuniver.ru \\ ${ }^{3}$ V.I. Vernadsky Crimean Federal University, Simferopol, Russia, viza_1986@ukr.net \\ ${ }^{4}$ Minin Nizhny Novgorod State Pedagogical University, Nizhny Novgorod, Russia, kmm-asb@mail.ru \\ ${ }^{5}$ Minin Nizhny Novgorod State Pedagogical University, Nizhny Novgorod, Russia, chelnelena@ gmail.com
}

\begin{abstract}
The development and active use of assessment tools based on computer, multimedia and communication technologies in professional education opens up new opportunities for training students. At the same time, there is a need to use tools that are adequate for the innovative development of evaluating the educational results of students, contributing to a more rapid and qualitative assessment of student activity. Placement of assessment tools is carried out on electronic educational platforms. The purpose of the article is to analyze the tools for evaluating e-course elements in Moodle. Features of using "Forum", "Wiki", "Test", "Lecture", "Task" and other electronic assessment tools are revealed.

The article presents a study in the form of expert evaluation, which allowed us to reveal and evaluate the capabilities of evaluation tools for the electronic educational platform Moodle.
\end{abstract}

Key words: Moodle, e-course, test, assessment tools.

\section{INTRODUCTION}

The formation and development of the information society has led to the widespread introduction of electronic tools in the field of education. The spread of computers, multimedia, and information and communication technologies has defined new requirements for solving educational problems. With the growth of information flows, the educational process becomes more dynamic. Consequently, the assessment of students' work should become more rapid for the implementation of qualitative formation of their professional competence. Many systems provide tools for evaluating student performance. For example, Articulate Storyline, which is a popular tool for creating e-learning materials. iSpring also allows you to design multimedia e-learning materials, accompanied by tools for evaluating work. In this article, we consider the possibilities of Moodle-an electronic educational platform that is most often used by higher education institutions for remote work with students. The tools provided by LMS Moodle allow you to solve the problem of performing a rapid assessment of students' work.

This e-learning platform includes a multi-functional test module. Test questions are managed via the "question Bank" [1]. These can be tests for input control, current control, or final control. This may be the test equipment. Moodle offers a wide range of features for instant automatic verification and evaluation of tasks; automatic statistical analysis of the test and its elements [2].

Assessment is also carried out using the course elements: Task, Forum, Wiki. By setting a task for students in Moodle, the teacher determines how students will present their work:

- as text;

- as a file (students upload a file containing the work to the course) [3];

- in the form of multiple files [4].

The task requires a creative response from the student. To place a task, the teacher selects "Add course element" in the selector [5]. Assessment is performed depending on the settings set by the teacher:

- one or more attempts;

- sending notifications to teachers;

- include a review in the text of the student's response;

- maximum file size;

- allow deletion [6];

- a maximum number of files to upload.

The specified parameters simplify the verification process, but, unlike the test, the assessment is made personally by the teacher [7]. On the main page of the site, there are "course Elements", where there is a link "Tasks" [8]. This way the teacher gets a summary table of results for all tasks in a particular course [9]. The information received by the teacher includes the type of task, deadline, and responses.

Moodle supports different types of forums:

a simple discussion (can be used to focus students ' attention on one specific topic); 
Olga I. Vaganova et al., International Journal of Advanced Trends in Computer Science and Engineering, 9(3), May - June 2020, 2488 - 2492

- a standard forum for General discussion (an open forum where students can start a new topic at any time);

- each student opens one topic (in this case, the number of created topics may be limited) [10].

In order to evaluate forum participants, you need to configure the options of the "Evaluation" group. The rating parameter can also be the number of messages sent by the user. If the message limit is reached, the participant will be blocked for a certain time [11].

Wiki makes it possible for students to work together on a document. Any of the participants can edit wiki articles [12]. When working together, the teacher uses the "History" function to track the contribution of each participant to the work and its evaluation [13].

Each teacher independently determines the importance and priority of using a particular tool to evaluate the work of students [14].

The purpose of this research is to analyze tools for evaluating e-course elements in Moodle. The research focuses on the role of assessment tools in student learning. The choice of an electronic assessment tool by a teacher is of high value.

\section{THEORETICAL FRAMEWORK}

Theoretical significance for our research is represented by the works of G. D. Bukharov, B. S. Gershunsky, E. V. Mashbits, and other researchers devoted to the topic of Informatization of education, the use of electronic means in the process of training students of higher educational institutions. Questions of the theory and practice of electronic learning are presented in the works of E. S. Polat, V. p. Tikhomirov and others. Many scientists consider individual electronic elements in professional education [15]. Halatsyn K. A. considers changes in students ' motivation when using e-learning tools [16]. The Moodle distance learning system was considered in the works of E. G. Gayevskaya And M. V. Kostikova. Many scientists focus on the tools Testing, Lecture, Forum as the most frequently used and effective in distance learning [17]. S. G. Grigoriev's works highlight the means that contribute to the organization of the educational process at a remote distance [18]. The content and possibilities of using Moodle are revealed in the works of O. A. Kovalev, A.V. Belozubov, and N. V. Volzhenina, who present it as a software package for creating distance learning courses. Among foreign scientists who have devoted their work to the study of e-learning using the tools of electronic educational platforms, it is worth noting Andrienko O. A. [19], Koshechko N. V. [20], Chirva, A. N. [21]. The characteristics and features of the tools of this electronic educational platform are considered in the works of G. V. Kravchenko, N. V. Maksimov, A.V. Mogilev and others. The concept of Moodle (Modular Object-Oriented Dynamic Learning Environment) in the professional education system is revealed as a modular object-oriented dynamic learning environment [22]. It is a learning management system focused primarily on the interaction between students and teachers [23]. It is used both for organizing distance courses and for supporting face-to-face training the organization of mixed training [24].

Moodle refers to the type of LMS - a learning management system (learning management system) [25]. It allows you to design, create and manage the resources of the information and educational environment, allows you to intensify work, minimize the loss of educational time [26].

Various types of tasks implemented on the platform allow you to evaluate individual knowledge of students and the level of formation of their competencies.

\section{METHODOLOGY}

The article presents tools for evaluating the educational results of students of higher education institutions using the electronic educational platform Moodle. When monitoring students ' educational activities, a Test, Task, forum, Wiki, and other elements are used. Teachers were asked to evaluate the assessment tools. The selection of experts was made from among the teachers of the higher educational institution. Competence was the main criterion for selecting experts. The self-assessment method was used. The most optimal form of expert assessment for our research is the aggregate index. Its calculation is based on experts ' assessment of their own knowledge, experience and abilities on a rank scale with the positions "low", "medium", "high". The first position is assigned the value 0 , the second -0.5 , and the third- 1 .

The expert group included teachers with a combined index of at least average (0.5). The primary numerical values of self-assessment $\mathrm{K}_{1}, \mathrm{~K}_{2}$, and $\mathrm{K}_{3}$ were obtained using a table-form question. Based on the numerical values of grades indicated by the + sign in the table, the coefficient of the teacher's competence level and the possibility of including him in the list of experts on the use of evaluation tools in the Moodle electronic course were calculated.

The group of experts included 42 teachers; whose combined index ranged from 0.5 to 1 .

We have developed a teacher questionnaire for a survey in order to get information about satisfaction with the tools for evaluating students' achievements in the electronic educational platform Moodle. The teachers evaluated the capabilities of various assessment tools for monitoring the Moodle course.

\section{RESULTS AND DISCUSSION}

The form of organization of the educational process is lectures, laboratory classes, and independent work. The lectures use Surveys, Tasks, and Tests. Tasks, Wiki, and 
Olga I. Vaganova et al., International Journal of Advanced Trends in Computer Science and Engineering, 9(3), May - June 2020, 2488 - 2492

Forum are used in independent work. Laboratory work is checked using Tasks and Tests.

The test allows you to automatically provide results. The average score of the test subjects is the arithmetic average of the scores of all students who performed the test. To perform test control, the teacher fills in the appropriate fields depending on the type of test question (multiple-choice, true/false, match, short answers, numeric answers, nested answers. To provide a response, Moodle contains a built-in editor that allows you to format texts, insert lists, and tables. Evaluation of the student's work on the forum is not possible without the personal participation of the teacher. Evaluating the work using Wiki also requires attention from the teacher, however, their personal participation in the process is not required. To add an assessment Forum to a course, teachers use the "course Elements" section [27]. Select a forum and configure It. In the "General" section, select its name, description, and type. The "Subscription and tracking" section allows you to configure the mode of students ' subscription to the Forum. To evaluate a performance, you can configure the options of the "Ratings" group. To configure the "Task" element, you must specify its type, evaluation method, evaluation category, and its scale and passing score. Using Moodle, the teacher receives a report on the activity of each student in the course of work. Tasks can be different, such as essays. The task involves a creative response from the student. The student presents it as a text or file.

The evaluation results are placed in the evaluation log. Only users with the appropriate permissions can edit ratings. The journal contains three sections: "assessment element", "category", and "assessment".

The teacher receives information about the student's activity on the course through a report [28]. The report is presented in three types: assessment report; student activity report; and course statistics.

Moodle allows the teacher to evaluate the student's work not only from 0 to 100 points, but also in the form of a word or phrase.

To check the task, Moodle gives the teacher the opportunity to use the "assessment summary". It reflects the number of participants who completed the task, the number of responses, and the number of responses that require evaluation.

To conduct the research, we had to carry out an expert selection of their number of teachers of higher education institutions (senior teachers, candidates of science). The primary numerical values of self-assessment were obtained using a tabular form question "Evaluate Your ability to use the assessment tools of the Moodle e-learning platform". Based on the numerical values of grades indicated by the + sign in the table, the coefficient of the teacher's competence level and the possibility of including him in the list of experts on the use of evaluation tools in the Moodle electronic course were calculated. The study is based on experts ' assessment of their own knowledge, experience and abilities on a rank scale with the positions "low", "medium", "high", as shown in table 1.

Table 1: "Results of self-evaluation by teachers of the ability to use the assessment tools of the electronic educational platform Moodle" (fragment)

\begin{tabular}{|l|c|c|c|}
\hline & $\begin{array}{l}\text { Hig } \\
\mathrm{h}\end{array}$ & $\begin{array}{l}\text { Middl } \\
\mathrm{e}\end{array}$ & Low \\
\cline { 2 - 4 } & 1 & 0.5 & 0 \\
\hline $\begin{array}{l}\text { The level of theoretical knowledge } \\
\text { of the use of Moodle Evaluation } \\
\text { Tools }\end{array}$ & + & & \\
\hline Practical Experience & & + & \\
\hline Ability to predict events & + & & \\
\hline
\end{tabular}

According to the results of the expert selection, 42 teachers were selected. To identify the most preferred tools for evaluating student performance in LMS Moodle, a survey was conducted among teachers. Figure 1 shows the results of processing the survey data.

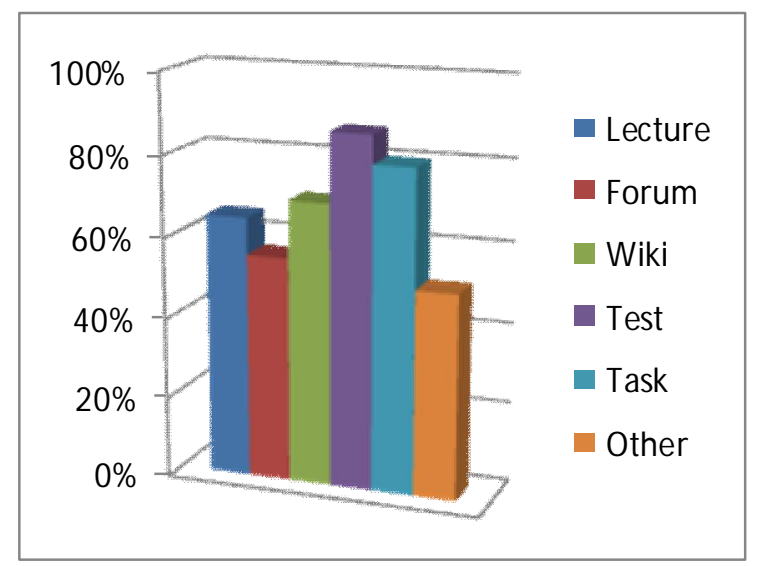

Figure 1: Results of processing the survey data to assess the capabilities of tools for evaluating student performance

According to most teachers, the most popular tools for assessing student performance are Test, Assignment, Wiki. Lecture and Forum are also of interest.

We have developed a teacher questionnaire for the survey to obtain information about satisfaction with student assessment tools in the Moodle electronic educational platform. The teachers expressed their opinion on how satisfied they are with the selected tools in the preparation of students of higher educational institutions. Table 2 shows the results of the survey. 
Olga I. Vaganova et al., International Journal of Advanced Trends in Computer Science and Engineering, 9(3), May - June 2020, 2488 - 2492

Table 2: " The results of statistical processing of satisfaction teachers tool s evaluation electronic educational Moodle Platform" (fragment)

\begin{tabular}{|c|c|}
\hline Questions & Answers \\
\hline $\begin{array}{l}\text { How are you satisfied with the verification } \\
\text { of theoretical training of students with the } \\
\text { tools the Moodle? }\end{array}$ & $\begin{array}{l}\text { - fully satisfied } \\
-89 \% \\
-\quad \text { partially } \\
\text { satisfied - } 11 \% \\
\text { - not satisfied - } \\
0 \%\end{array}$ \\
\hline $\begin{array}{l}\text { How are you satisfied with the level of } \\
\text { verification of practical training of students } \\
\text { using the Moodle tools? }\end{array}$ & $\begin{array}{l}\text {-completely } \\
\text { satisfied - } 58 \% \\
-\quad \text { partially } \\
\text { satisfied - } 42 \% \\
\text { - not satisfied - } \\
0 \%\end{array}$ \\
\hline $\begin{array}{l}\text { How are you satisfied with these tools for } \\
\text { assessing the given subject area? }\end{array}$ & $\begin{array}{l}\text {-fully satisfied } \\
-91 \% \\
-\quad \text { partially } \\
\text { satisfy - } 9 \% \\
\text { - do not satisfy } \\
-0 \%\end{array}$ \\
\hline $\begin{array}{l}\text { How are you } \\
\text { the functionality of the evaluation }\end{array}$ & $\begin{array}{l}\text { - fully satisfied } \\
-85 \% \\
-\quad \text { partially } \\
\text { satisfied - } 15 \% \\
\text { - not satisfied } \\
-0 \%\end{array}$ \\
\hline $\begin{array}{l}\text { How are you satisfied with the ability to } \\
\text { customize student assignments in Moodle? }\end{array}$ & $\begin{array}{l}\text { - fully satisfied } \\
-87 \% \\
-\quad \text { partially } \\
\text { satisfied - } 13 \% \\
\text { - not satisfied - } \\
0 \%\end{array}$ \\
\hline $\begin{array}{l}\text { Are you satisfied with the objectivity of the } \\
\text { results? }\end{array}$ & $\begin{array}{l}\text { - fully satisfied } \\
-76 \% \\
-\quad \text { partially } \\
\text { satisfied - } 24 \% \\
\text { - not satisfied - } \\
0 \%\end{array}$ \\
\hline
\end{tabular}

Statistical data processing allowed to establish a high level of satisfaction of respondents with assessment tools provided by Moodle.

\section{CONCLUSION}

In the process, an analysis of the tools for evaluating the elements of the electronic course in Moodle was carried out. A study to identify the most effective tools for assessing students in the electronic educational environment of Moodle made it possible to establish that, despite the variety of assessment tools, Tests are the most popular and in demand. Assignment and Wiki tools are also popular with educators. According to the results of the survey, it can be said that respondents note the possibility of a qualitative verification of students' theoretical knowledge using the Moodle assessment tools. Additional tools are required to test practical training, but Moodle tools allow you to establish the primary formation of practical skills. Teachers also believe that the Moodle assessment tools are highly effective in any subject area. They allow you to choose specific settings for the entire group of students and, if necessary, for each student. Using the Moodle assessment tools, teachers have the opportunity to get fairly objective results of training students.

\section{REFERENCES}

1. Pliushch, V.M. (2018). Independent work of students as a factor of improving education quality. Balkan Scientific Review, 1, 69-71.

2. Raven, J. (2017). Education and Sociocybernetics, Azimut nauchnykh issledovaniy (Azimuth of Scientific Researches: Economics and Management), 6, 3 (20), 289-297.

3. Aleksieienko-Lemovska, L.V. (2019). The activity approach as a basis for preschool teachers' methodological activities, Humanitarian Balkan Research, 3, 4(6), 10-14.

4. Ilyashenko, L. K., Smirnova, Zh. V., Vaganova, O. I. Chelnokova, E. A., Kaznacheeva, S.N. (2019). Methods of Conducting Practical Training on the Subject "Power Sources for Welding", International Journal of Mechanical Engineering and Technology, 10 (02), 908-917.

5. Andriushchenko, T. K., (2018). Personal aspects of pedagogue's innovative culture, Scientific Vector of the Balkans, 1, 13-16.

6. Bakharev, N. P., (2019). Creativity - a prerequisite for the formation of professional competences in specialists of technical direction of training, Scientific Vector of the Balkans, 3, 4 (6), 17-21.

7. Bulayeva, M.N., Aleshugina, Ye.A., Maksimova, K.A. (2019). Modeling of the process of formation competence of teachers in university. Baltiyskiy gumanitarnyy zhurnal (Baltic Humanitarian Journal), 8, 3 (28), 21-24. (in Russ.).

8. Cirdan, A.P. (2019). Innovative technologies of professional training of future economists in the system of continuous education. Humanitarian Balkan Research, 2(4), 27-30.

9. Donetskova, O.YU. (2019). Modernization of the modern education system in Russia. Baltiyskiy gumanitarnyy zhurnal (Baltic Humanitarian Journal), 8, 2 (27), 37-39. (in Russ.).

10. Filchenkova, I.F. (2019). Educational management of innovative activity of teachers as an object of pedagogical research. Vestnik Mininskogo universiteta (Vestnik of Minin University), 2019. 7 (4), 3. (in Russ.).

https://doi.org/10.26795/2307-1281-2019-7-4-3

11. Myalkina, E.V. (2019). Diagnostics of the education quality in the higher educational 
institution. Vestnik Mininskogo universiteta (Vestnik of Minin University), 7, (3), 4. (in Russ.)

https://doi.org/10.26795/2307-1281-2019-7-3-4

12. Oros, I.I. (2018) The role of international connections in the development of the adult education system. Humanitarian Balkan Research, 1, 57-59.

13. Osadchenko, I.I. (2019). Key concepts of situational training technology in preparing future teachers. Scientific Vector of the Balkans, 1 (3), 46-49.

14. Pichugina, G.A., Bondarchuk, A.I. (2019a). Structure of the training case in the organization of the educational process. Humanitarian Balkan Research, 2(4), 5-7.

15. Pichugina G. A., Zhilyakova D. A. (2019b) Structuring the organization of the process of creativity. Scientific Vector of the Balkans, 3, 3 (5), 55-58.

16. Halatsyn, K.A., Feshchuk, A.M. (2019). Diagnosing motivational-and-valuable component of the communicative culture of students in higher technical educational institutions, Balkan Scientific Review, 3, 2 (4), 17-20.

17. Pisarenko, D. A. (2019). Evaluation of extracurricular activities of university students with a competency-based approach, Scientific Vector of the Balkans, 3, 3 (5), 37-40.

18. Grigoriev S. G., Shabunina V. A., Tsarapkina Ju. M., Dunaeva N. V. Electronic library system as a means of self-development of students of digital generation $Z$ (on the example of studying the course "Basics of the counselor activity"), Scientific and technical libraries. 2019. No. 7. Pp. 78-99. 29.

https://doi.org/10.33186/1027-3689-2019-7-78-99

19. Andrienko, O.A. (2019). Network educational technologies and their use when working with students, Humanitarian Balkan Research 2019, 1(3), 5-7.

20. Koshechko, N.V. (2018). Innovations from educational discipline "Pedagogical conflictology" in professional preparation of students. Scientific Vector of the Balkans, 1, 59-63.

21. Chirva, A.N., Chirva, O.G. (2018). Contents and method of professionally oriented training of informatic disciplines of future teachers of technologies, Scientific Vector of the Balkans, 1, 27-31.

22. Kamenez, N.V., Smirnova, Zh. V., Vaganova, O. I., Bystrova, N.V., Tsarapkina, J.M., (2019). Development of Instructing Techniques in Professional Training, International Journal of Mechanical Engineering and Technology, 10(02), 899-907.

23. Andrienko, O.A. (2019). On the need to apply gaming training technologies, Balkan Scientific Review, 2 (4), $5-8$.

24. Klinkov, G.T. (2018). The specificity of manifestation of pedagogical communication as a special construct, Scientific Vector of the Balkans, 1, 51-52.
25. Vaskovskaya, G.A. (2018). Features of implementation of pedagogical technologies of profile training, Balkan Scientific Review, 1, 76-79.

26. Vinothini K., Aida M., Heng C. Y., (2019). CodeCube: Active Learning for STEM, International Journal of Advanced Trends in Computer Science and Engineering, 8 (1.3), 293-299. https://doi.org/10.30534/ijatcse/2019/5581.32019

27. Syamsul, B. Z., Emram, Y., (2019). Perceptions of Computational Thinking in Game Based Learning for Improving Student Problem Solving Skills, International Journal of Advanced Trends in Computer Science and Engineering, 8 (1.3), 181-184. https://doi.org/10.30534/ijatcse/2019/3681.32019

28. Irwan, M. I., Siti, K., Anis, Mohd, E. I. Kamaruzzaman, I., Norazah, M. N. (2019). Impact of Games on Motivation, Attention and Skills in Pre-school Children, International Journal of Advanced Trends in Computer Science and Engineering, (2019), 8 (1.3), 157-159.

https://doi.org/10.30534/ijatcse/2019/3181.32019 